\title{
AS ZONAS DA ARTE
}

RAFAEL VOGT MAIA ROSA entrevista o crítico de arte, curador e professor de Yale Robert Storr

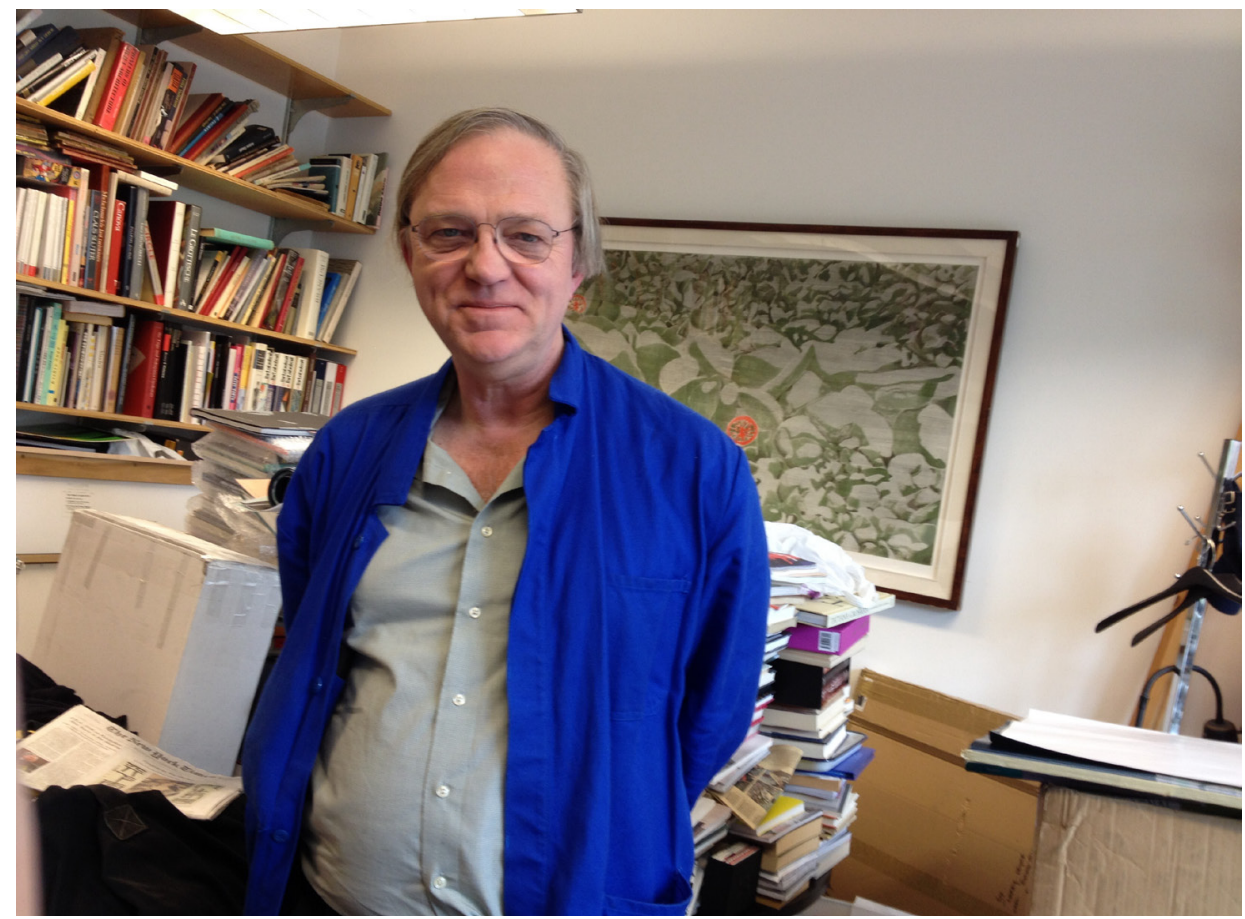

foto: Rafael Vogt Maia Rosa

Na sala de Robert Storr na Escola de Artes de Yale, da qual é o diretor, mal cabem duas pessoas. Uma vez sentado em uma poltrona baixa, só é possível ver o crítico e artista plástico através das colunas de livros e catálogos empilhados por todo lado. "Eu não leio isso", ele diz, enquanto procuramos um espaço vago com boa luz para foto. De fato, apesar da bibliografia ostensiva, não é difícil perceber que Storr é o contrário do estereótipo do intelectual sisudo e muito menos do crítico infeliz por não ser artista. Apesar de poder ser bastante contundente em seus textos como na crítica que publicou em 2012 à nova direção do Museu de Arte 
Contemporânea de Los Angeles[1] -, é alguém que estabelece o elogio às diferenças e o bom humor como terreno comum para se começar a falar de arte.

Curador do departamento de pintura e escultura do Museu de Arte Moderna de Nova York, de 1990 a 2002, e responsável pela 52a edição da Bienal de Veneza, para qual propôs o tema "Pensar com os sentidos", Storr é uma das mais respeitadas e solicitadas figuras no cenário artístico norte-americano atual. Nesta entrevista, concedida em setembro de 2013, ele fala sobre uma concepção não consensual a respeito do modernismo, da relação das artes plásticas com a crítica e outras artes, bem como sobre aspectos pontuais da questão da teatralidade no contexto contemporâneo das artes plásticas.

\section{Em uma entrevista recente, você mencionou dois pintores} contemporâneos, Raoul De Keyser e Tom Nozkowski, que fizeram sucesso tardiamente. Isso, por si, poderia ser visto como um sintoma de um processo artístico menos programático, mas a obra deles, especialmente de De Keyser, me pareceu de algum modo distante de um ideário modernista, dado seu humor e variedade estilística. Quero dizer, não exatamente "moderno a despeito do modernismo" [2], mas simplesmente "outra coisa". O que acha dessa impressão e quais você diria que são as aspirações da pintura hoje?

Robert Storr - A primeira questão é que eu não acredito que nós necessariamente concordemos a respeito do que seja o modernismo. Eu não tenho certeza exatamente do que você pensa, mas eu não creio que o modernismo jamais tenha sido uma coisa. Eu não creio que ele tenha sido sempre necessariamente sério, não acredito que exista uma característica particular que você possa dizer que é a essência do modernismo e, assim, eu vejo todas as razões para pensar em Raoul De Keyser como um artista modernista. Há uma longa tradição na arte moderna, que se aplica também a Nozkowski, de uma inventividade divertida, de um tipo de evocação do mundo natural, e assim por diante... Mesmo no Brasil. Você pode ver o trabalho de artistas brasileiros concretos e neoconcretos e vai encontrar muitos 
temperamentos diferentes, muitas características diversas. Portanto, eu simplesmente vejo De Keyser como sendo um modernista de sua geração, e eu o vejo como uma instância de uma sensibilidade europeia altamente cosmopolita, na qual ele trabalha por uma série de fases - abstrata, pop e assim por diante --, até chegar a sua síntese própria. Quanto ao que pode ser feito no futuro... Existem diversas coisas a serem feitas. E não creio que exista uma missão para o modernismo, mas muitas. Como sempre digo, a substância do modernismo são as controvérsias a respeito do que o modernismo deve ser; e as respostas são tão numerosas quanto o são os bons artistas.

Em palestra dada aqui, em 2010, na Escola de Arte Dramática, David Hare afirmou que as atividades da crítica e da criação artística são virtualmente opostas. Ele disse também que a peculiaridade da profissão do artista seria a de ser capaz de lidar com o destino de ser julgado, sempre, enquanto a do crítico, consequentemente, seria a de julgar. Presumindo que você é ambos, artista e crítico... Storr - Sim, eu sou.

...pois então, como você vê esse aparente antagonismo? Storr - Eu discordo. E penso que o desacordo possa ter a ver com diferentes experiências de vida. As pessoas do meio teatral recebem avaliações críticas o tempo todo e frequentemente recebem avaliações negativas e isso as faz supersensíveis, as faz desgostar de críticos. Por outro lado, ninguém menos que Oscar Wilde escreveu um longo diálogo em que essencialmente dissolve as distinções entre arte e crítica e, obviamente, nas artes visuais, muitos de nossos melhores escritores são ou foram artistas. Pode-se pensar em Delacroix, Van Gogh, Donald Judd, pode-se pensar em Sol Lewitt, Robert Morris e a lista segue... Quero dizer, no caso do Brasil você encontra a mesma situação: Tarsila [do Amaral], por exemplo, escreveu bastante, e seu marido [Oswald de Andrade] também. Assim, essa ideia de que há uma diferença categórica entre arte e crítica é uma ficção. De todo modo, eu posso entender as motivações que o levam a não se sentir bem em relação aos críticos. Eu de fato acredito que artistas fazem algo que críticos nem sempre fazem, porque relativamente poucos críticos são verdadeiramente escritores. Mas os maiores são escritores, e nós lemos seus textos sobre artistas que 
seriam completamente irrelevantes. Portanto, se lemos Baudelaire sobre Constantin Guys não é porque Guys é uma figura importante, mas porque Baudelaire escreveu algo extraordinário sobre as possibilidades que acreditou que esse artista representava.

Se você tomar a obra de Matthew Barney como exemplo - e ele atleta, jogador de futebol americano e aluno aqui, enfim... --, existem tantos elementos de teatro, música e cinema envolvidos que é uma espécie de eufemismo chamá-la de "arte visual”. Por outro lado, parece que é um desenvolvimento histórico específico das artes visuais que provê as bases de sua poética. Qual é, afinal, a singularidade desse campo, o que o diferencia de outras linguagens artísticas?

Storr - Esse é um tópico bastante amplo e complicado. Quero dizer, era uma vez, e particularmente neste país, nos anos 40 e 50, com Clement Greenberg, essa ideia de que cada mídia tinha suas propriedades essenciais. E que aquelas obras de arte que combinassem as propriedades de diferentes mídias eram de algum modo inferiores. E havia uma forte argumentação contra o teatral nas artes visuais, como sendo, de alguma maneira, inferior à pura pintura ou à pura escultura.

\section{Você acha essa questão datada?}

Storr - Eu acho que foi um erro de início e continua sendo. Não acredito que estivesse errado quando Greenberg promulgou isso, mas não acredito que ele tenha entendido as implicações do que disse, e o mesmo para Michael Fried, que estendeu isso ainda mais adiante. Então, não vejo qualquer razão para se aceitar isso como um a priori. Certamente Picasso não se importava nada com o que era absolutamente pintura, absolutamente desenho, e daí a colagem, claro, misturou tudo ainda mais. De todo modo, retomando a questão, a obra que Matthew [Barney] faz, ela pertence a uma longa tradição de apagamento dessas distinções. Recentemente ele tem sido mais "aberto" em sua homenagem a Joseph Beuys, por exemplo. E Beuys obviamente também provém de uma tradição. Assim, penso que é possível ver a performance e a instalação como uma ampla plataforma de práticas artísticas, desde o século 19, ao menos, ou talvez antes ainda, no século 18 , com as máscaras e formas como essas; e que nós estamos vendo permutações muito interessantes, muito novas - algumas mais, outras menos -, de uma longa história 
desse tipo de prática artística que inclui os acionistas de Viena, Itália, Japão, que inclui muitas e muitas tendências, e Matthew é provavelmente o mais cinematográfico que já vimos; mas, por outro lado, ele é o mais conservador, teatral; sua afinidade com a Grande Ópera, com as trupes do Século 19. Ele é na verdade bastante conservador, apesar de outras coisas que faz serem muito inovadoras.

Um ex-aluno desta universidade publicou um livro no ano passado intituladoSexo e Deus em Yale.

Storr - Ele encontrou ambas as coisas, sexo e Deus em Yale? (risos)

Não tenho certeza quanto a deus, mas sexo, de certa maneira, eu diria que sim.

Storr - Eu fico feliz por ele.

Pois é... Em todo caso, em um dos capítulos, ele transcreve a seguinte notícia publicada no jornal da universidade: “A aluna de artes plásticas Aliza Shvarts (classe de 2008) quer fazer uma declaração. A partir da próxima quinta-feira, Shvarts estará apresentando o seu projeto de conclusão de curso, uma documentação de um período de nove meses durante os quais ela se auto-inseminou artificialmente "o mais frequentemente possível” enquanto tomou periodicamente medicamentos para induzir abortos. Sua exposição incluirá gravações em vídeo desses abortos induzidos, bem como mostras de sangue obtidas durante esse processo".

Storr - Eu não li o livro, mas conheço o caso.

Como diretor da escola, você considera que há limites éticos para propostas nesse sentido?

Storr - Eu estive envolvido intimamente, e existem questões sobre as quais eu não posso falar porque dizem respeito à privacidade de um aluno. Mas minha visão é a seguinte: nesse caso, em particular, o que uma mulher fez foi de sua inteira escolha fazer; se ela estivesse fora de um ambiente acadêmico, se ela estivesse fazendo coisas como as que os acionistas fizeram, como Yoko Ono fez, ou não importa quem no domínio público, eu não teria nenhum comentário a respeito; caberia a ela e eu, como membro da audiência, iria ponderar a respeito. No 
ambiente acadêmico, a instituição não deve encorajar alunos, possibilitar que eles façam coisas quando muito jovens que podem acabar sendo bastante prejudiciais a longo prazo. E nessa circunstancia em particular, ela não estava sendo completamente franca em relação ao que estava fazendo e acabou envolvendo a universidade em um processo que nós não teríamos aprovado se tivéssemos sido comunicados de início do que se tratava realmente. E, se assim fosse, nós enfim teríamos que dizer que não iríamos avaliar o trabalho, porque não concordávamos com ele, e procurar outra obra do aluno que pudéssemos considerar.

O tema deste número da revista Celeuma é o da inter-relação das artes. Você acabou de abordar a questão, mas poderia falar mais especificamente algo a respeito da influência da música no seu trabalho?

Storr - Bom, eu vivo com uma musicista e escuto muita música. Mas não envolvo música com nada que eu faço. Não é parte de meu projeto. Mas trabalho com muitos artistas que têm a música como algo essencial no que fazem. Bruce Nauman, por exemplo. Portanto, eu vejo a música como um ingrediente das artes visuais com muita frequência atualmente. $\mathrm{E}$ acho bastante interessante. O hip-hop teve uma profunda influência em obras feitas não só por negros nos EUA, mas no mundo inteiro, porque a linguagem do hip-hop, as rimas têm um tipo de plasticidade que é basicamente um jogo de palavras no sentido wittgensteiniano, certo? Assim, tudo isso é muito interessante pra mim, mas não é o que eu faço.

\section{Certo...}

Storr - Agora, retomando sua questão anterior, e também porque se trata de uma publicação brasileira, obviamente, o que Lygia Clark, Oiticica e outros fizeram está bastante ligado à parte de uma tradição da qual Barney provém. Eu diria que a deles é mais radical do que a dele. Internamente, pode-se olhar para a tradição da confluência de mídias e da teatralidade na arte e fazer julgamentos baseados não no fato de ser ou não ser arte, mas a partir de uma zona determinada. Por exemplo, Allan Kaprow se queixa de que não se deveria falar em "performance" e não se deveria falar em "instalação", porque ressaltam o que ele chama de "qualidades cenográficas e teatrais". Sua preferência era por "environments" [ambientes] e happening que minimizam o "cenográfico". 
Isso permite um diálogo interno entre práticas, no qual é possível tomar diferentes posições; acredito que seja mais útil que reduzi-lo à pintura e escultura tradicionais.

Dito isso, você não pensa, então, que a pintura é um meio mais conservador ou tradicional?

Storr - São coisas diferentes. Mais tradicional significa "com mais tradição". Conservador significa se ater a algo contra as pressões por mudanças. A boa pintura mantém-se transformando. Ela pode ser tradicional e progressista ao mesmo tempo. Conservador geralmente mantém-se atrás ou olha pra trás.

\section{Mantém-se transformando, mas não reagindo ao próprio modernismo...}

Storr - Sim. E, de novo, não acredito que nós concordemos a respeito do que seja o modernismo. Eu penso que "modernismo" tem uso comum hoje; o pós-modernismo, como uma ideia que o toma por esse uso comum, é uma falácia. É altamente suspeito. O modernismo nunca chegou perto de ser o que fórmulas norte-americanas da metade do século 20 disseram que é. Logo, sou totalmente a favor de se superar isso, mas não em nome de algo que vem depois do modernismo, mas em nome de se restaurar a complexidade e diversidade do que ele foi em suas origens.

\section{Também quanto à noção de "planaridade da pintura moderna" e exploração das especificidades desse meio...}

Storr - A pintura vem explorando seu próprio meio por toda a sua história, certo? Planaridade foi uma característica muito específica que surgiu na França, e se fixou na era pós-impressionista, e que Clement Greenberg revisitou. Mas eu conheço muitos pintores que não fazem pinturas planares. Elisabeth Murray não faz pinturas planares, Bob Ryman não faz pinturas planares, Frank Stella não faz pinturas planares. Portanto, a ideia de planaridade já estava vencida no minuto em que alguém a proferiu.

Em um ensaio sobre a artista brasileira Jac Leirner, você começa com a frase "Foi amor à primeira vista". Eu estava pensando em um texto de 
Agamben sobre a natureza da amizade, em que ele fala da etimologia dessa palavra, sua íntima relação com a própria filosofia, o conhecimento, mencionando também, a partir de uma pintura de Serodine, a questão da "excessiva proximidade" - a que se poderia talvez acrescentar a ideia de uma confiança absoluta. Você acredita que a distância é um requisito para a boa crítica?

Storr - É um requisito não só para a boa crítica, mas para a boa arte. "Amor à primeira vista" não é a mesma coisa que confiança absoluta. Eu não confio em ninguém absolutamente. Eu não confio em minha companheira absolutamente - e ela não confia em mim... (risos) No sentido de que nós nunca estamos em total acordo com outra pessoa, certo? E nossa experiência de vida nunca está em total acordo com a de outra pessoa. Confiança é uma questão da latitude que você suporta que algo seja diferente de você. E eu confio em uma ampla latitude de obras que valorizo. Mas amor, atração e envolvimento não significam identidade.

[1] http://www.huffingtonpost.com/robert-storr/moca-paulschimmel_b_1699141.... (http://www.huffingtonpost.com/robert-storr/moca-paulschimmel_b_1699141.html)

[2] Título de livro publicado por Robert Storr por ocasião da milésima exposição realizada no MoMA, em 2002. 